\section{Scientific journal}

\section{PHYSICAL AND MATHEMATICAL EDUCATION}

Has been issued since 2013.

Науковий журнал

ФІЗИКО-МАТЕМАТИЧНА ОСВІТА

Видається з 2013.
ISSN 2413-158X (online)

ISSN 2413-1571 (print)

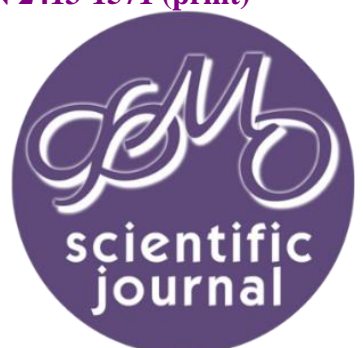

Лукашова Т.Д., Страх О.П. Інтегрований підхід щодо визначення похідної функцій, заданих на неперервних та дискретних множинах. Фізико-математична освіта. 2021. Випуск 4(30). С. 76-81.

Lukashova T., Strakh O. Integrated approach to definition of derivative of functions, which is defined on continuous and discrete sets. Physical and Mathematical Education. 2021. Issue 4(30). P. 76-81.

DOI 10.31110/2413-1571-2021-030-4-011

удк $[517.2+519.1+517.9+519.6](378)$

Т.Д. Лукашова

Сумський державний педагогічний університет імені А.С. Макаренка, Україна tanya.lukashova2015@gmail.com ORCID: https://orcid.org/0000-0002-1465-9530

О.П. Страх

Сумський державний педагогічний університет імені А.С. Макаренка, Україна strah_o@ukr.net ORCID: https://orcid.org/0000-0002-7680-5716

\title{
ІНТЕГРОВАНИЙ ПІДХІД ЩОДО ВИЗНАЧЕННЯ ПОХІДНОӦ ФУНКЦІЙ, ЗАДАНИХ НА НЕПЕРЕРВНИХ ТА ДИСКРЕТНИХ МНОЖИНАХ
}

АНОТАЦІЯ

Важливим елементом у підготовці майбутнього фахівця у галузі математики є набуття ним комплексних знань шляхом вивчення узагальнюючих теорій та методів, за допомогою яких визначаються основні фундаментальні поняття. На сьогодні існує цілий ряд таких теорії і їх використання виокремлюється навіть у самостійні наукові напрямки. Застосування елементів узагальнення та порівняння об'єктів вивчення різних математичних дисциплін у навчальному процесі також відіграє важливу роль в побудові міждисциплінарних зв'язків, які у свою чергу сприяють всебічному розвитку майбутнього спеціаліста, реалізації його потенціалу у науковій та професійній діяльності.

Формулювання проблеми. Аналізуючи основні положення диференціального та різницевого числень, неважко помітити значну схожість між властивостями похідної та різницевого оператора, що є ключовими характеристиками функцій, які визначені на неперервних та дискретних множинах відповідно. Виявляється, що ця схожість не випадкова, івказані поняття є частинними випадками поняття дельта-похідної функції.

Матеріали і методи. Авторами використовувались наступні методи: системний аналіз наукової, навчальної та методичної літератури; порівняння та синтез теоретичних положень; спостереження за ходом педагогічного процесу; узагальнення власного педагогічного досвіду та досвіду колег з інших закладів вищої освіти. Окрім того, були використані деякі загально математичні та спеціальні методи диференціального та різницевого числень $і$ теорії часових шкал.

Результати. У статmі розглянуто загальний підхід до вивчення двох фундаментальних математичних понять - поняття похідної та різницевого оператора з точки зору спеціальної теорії часових шкал, а також шляхи використання такого підходу щодо встановлення зв'язків між різними математичними теоріями з метою формування у студентів цілісного уявлення про математичні об'єкти, їх властивості та застосування.

Висновки. Встановлення зв'язків між моделями і методами дослідження, які використовуються при вивченні різних математичних дисциплін, що входять у програму підготовки майбутніх фахівців-математиків, дозволяє срормувати у студентів цілісне уявлення про математичні об'єкти, алгоритми та теорії, і як наслідок, робить їх знання системними і практично більш значущими. Це сприяє інтелектуальному розвитку студентів, формуванню в них системних математичних знань, підвищенню рівня математичної грамотності та інтересу до предмету.

КлЮчОВІ СлОвА: похідна функції, різницевий оператор, дельта-похідна, диференціальне числення, різницеве числення, неперервна множина, дискретна множина.

\section{ВСТУП}

Постановка проблеми. Одним із завдань вищої освіти $€$ формування у студентів умінь комплексного бачення проблеми, ії аналізу та системного вирішення. Реалізації цього завдання значною мірою сприяє інтеграція знань студентів з різних дисциплін, їх подальший синтез та комплексне застосування на практиці та в майбутній науковій та професійній

(C) Т.Д. Лукашова, О.П. Страх, 2021. 
діяльності. Яскравим прикладом такої інтеграції може слугувати вивчення поняття дельта-похідної функції, яке узагальнює поняття похідної та різницевого оператора, що $є$ ключовими характеристиками функцій, заданих на неперервних та дискретних множинах відповідно.

У даній статті розглядається можливість впровадження загального підходу до вивчення вказаних понять та його використання для встановлення міждисциплінарних зв'язків дискретної математики, математичного аналізу (диференціального числення) та теорії диференціальних рівнянь, що входять у цикл професійної підготовки майбутніх вчителів математики, а також формування цілісного уявлення про вказані математичні об'єкти, їх властивості та застосування. Окремі шляхи встановлення таких зв'язків між курсами дискретної математики та диференціальних рівнянь були розглянуті авторами в роботі (Страх\&Лукашова, 2021).

Аналіз актуальних досліджень. Донедавна панівне положення в математиці займало вивчення неперервних функцій, що було основою всіх застосувань математики у фізиці та техніці. Проте, з середини XX століття у зв'язку з бурхливим розвитком електронно-обчислювальної техніки, ядерної фізики, квантової механіки, теорії програмування та генної інженерії перед математикою постали якісно нові задачі, розв'язати які засобами класичного аналізу виявилося неможливо або занадто складно. Почалося відродження інтересу до дискретної математики, яка оперує дискретними (в тому числі й скінченними) множинами та функціями, визначеними на таких множинах. Сучасна обчислювальна техніка і накопичений досвід дозволяють за допомогою так званих різницевих схем наближено розв'язувати достатньо складні завдання, що погано піддаються дослідженню іншими методами.

Як відомо, ключове місце в диференціальному численні відіграє поняття похідної функції. Похідна як базова характеристика функцій, заданих на неперервних множинах, має численні застосування не лише в математиці, а й у ряді інших дисциплін. Для дискретно заданих функцій аналогом похідної виступає так званий різницевий оператор або скінченна різниця (Андерсон, 2004; Гельфонд, 1959; Ядренко, 2004). Скінченні різниці широко використовуються при інтерполяції в математичних таблицях, при підсумовуванні числових рядів, у наближених обчисленнях інтегралів та знаходженні розв'язків диференціальних рівнянь, а також у будь-якій ситуації, де треба описати поведінку об'єкта, характеристики якого дискретно змінюються під впливом певних факторів (у часі чи просторі). Наприклад, для термостата потрібен певний час, щоб відреагувати на зміну температури, тому він реагує не на поточну температуру, а на ту, що була хвилину назад.

Враховуючи, що диференціальне числення займається вивченням границь відношень різниць, а різницеве числення - самими різницями, то природно, що між цими двома теоріями існує багато паралелей. Відповідна теорія була побудована наприкінці XX століття німецьким математиком Стефаном Хільгером. Ним було уведено поняття $\Delta$-похідної, що об'єднує в собі поняття похідної та різницевого оператора, і оперує функціями, заданими на неперервно-дискретних часових інтервалах (множинах) (Bohner\&Peterson, 2001; Kelley\&Peterson, 2001).

Метою статті $\epsilon$ огляд інтегрованого підходу до вивчення похідної та різницевого оператора з точки зору теорії часових шкал, а також дослідження можливостей використання цього підходу щодо встановлення зв'язків між різними математичними курсами з метою формування цілісного уявлення про математичні об'єкти та теорії.

\section{МЕТОДИ ДОСЛІДЖЕННЯ}

У статті використано наступні теоретичні та емпіричні методи досліджень: системний аналіз наукової, навчальної та методичної літератури; порівняння та синтез теоретичних положень, розкритих в науковій та навчальній літературі; спостереження за ходом педагогічного процесу; узагальнення власного педагогічного досвіду та досвіду колег з інших закладів вищої освіти. Окрім того, були використані деякі загально математичні та спеціальні методи диференціального та різницевого числень і теорії часових шкал.

\section{РЕЗУЛЬТАТИ ДОСЛІДЖЕННЯ}

Одним з основних понять диференціального числення, яке як інструмент дослідження широко використовується не лише у математичному аналізі, а й у цілому ряді інших дисциплін (зокрема, в алгебрі й теорії чисел, теорії диференціальних рівнянь, чисельних методах, варіаційному численні, математичному програмуванні та фізиці), $\epsilon$ поняття похідної функції. В математичному аналізі в основу визначення похідної функції дійсного (комплексного) аргументу покладено поняття границі (див., наприклад, Фіхтенгольц, 1967).

Означення 1. Похідною функції $f(x)$ в заданій точці $x=x_{0}$ з області їі визначення (та неперервності) називається число

$$
f^{\prime}\left(x_{0}\right)=\lim _{\Delta x \rightarrow 0} \frac{f\left(x_{0}+\Delta x\right)-f\left(x_{0}\right)}{\Delta x}
$$

що є границею відношення приросту функції до приросту $\Delta x$ аргумента за умови, що величина $\Delta x$ прямує до нуля (i вказана границя існує).

Означення 1 можна переформулювати, застосовуючи визначення границі (наприклад, за О. Коші). Тоді похідну функції в точці можна визначити наступним чином.

Означення 2. Число $f^{\prime}\left(x_{0}\right)$ називається похідною заданої функції $f(x)$ в заданій точці $x=x_{0}$ з області їі визначення тоді і тільки тоді, коли

$$
\forall \varepsilon>0 \exists \delta(\varepsilon):\left|x-x_{0}\right|<\delta(\varepsilon) \Longrightarrow\left|f(x)-f\left(x_{0}\right)-f^{\prime}\left(x_{0}\right) \cdot\left(x-x_{0}\right)\right| \leq \varepsilon\left|x-x_{0}\right| .
$$

3 іншого боку, поняття границі можна ввести не у кожному полі або кільці. Зокрема, воно не застосовне в полі раціональних чисел (бо не кожна послідовність раціональних чисел має границею раціональне число) та й узагалі в усіх скінченних кільцях та полях. У цих випадках виникає потреба означити похідну функції без використання поняття границі. Так, у курсі алгебри і теорії чисел поняття похідної многочлена вводиться наступним чином (Завало, 1985).

Означення 3. Похідною многочлена $f(x)=a_{n} x^{n}+\cdots a_{1} x+a_{0}$ з коефіцієнтами з кільця К називають многочлен $f^{\prime}(x)=n a_{n} x^{n-1}+\cdots 2 a_{2} x+a_{1}$. 
Вважають також, що похідна від многочлена нульового степеня та нуль-многочлена дорівнює нулю, тобто якщо $f(x)=$ const, , $f^{\prime}(x)=0$.

Отже, в алгебрі поняття похідної многочлена над довільним кільцем (полем) вводиться за домовленістю (як многочлен певного виду). Зрозуміло, що при такому підході за певних обмежень зберігаються й основні правила диференціювання (для знаходження похідної від суми, добутку, частки многочленів).

В курсі дискретної математики (у розділі «Різницеве числення») для функцій, заданих на множині натуральних чисел, розглядається поняття різницевого оператора, яке фактично є дискретним аналогом поняття похідної у класичному розумінні (Андерсон, 2004).

Означення 4. Нехай область визначення функції $f(x)$ разом з точкою $x$ містить точку $(x+1)$. Різницевим оператором (оператором спадної різниці або різницею першого порядку) функції $y=f(x)$ називається вираз виду

$$
\Delta f(x)=f(x+1)-f(x) \text {. }
$$

Приклад 1. Знайти значення різницевого оператора від функцій $f(x)=x, p(x)=2^{x}, g(x)=x^{2}, h(x)=x !$.

$$
\begin{aligned}
& \text { Виходячи з означення 4, маємо: } \\
& \Delta x=(x+1)-x=1 \text {; } \\
& \Delta 2^{x}=2^{(x+1)}-2^{x}=2^{x}(2-1)=2^{x} \\
& \Delta x^{2}=(x+1)^{2}-x^{2}=2 x+1 \text {, } \\
& \Delta x !=(x+1) !-x !=(x+1-1) \cdot x !=x \cdot x ! .
\end{aligned}
$$

Значення різницевого оператора від деяких елементарних функцій наведено у Таблиці 1.

Таблиця 1

Значення різницевого оператора від основних елементарних функцій

\begin{tabular}{|c|c|c|c|}
\hline $\boldsymbol{f}(\boldsymbol{x})$ & $\Delta \boldsymbol{f}(\boldsymbol{x})$ & $\boldsymbol{f}(\boldsymbol{x})$ & $\Delta \boldsymbol{f}(\boldsymbol{x})$ \\
\hline$a \in \mathbb{N}$ & 0 & $\frac{1}{x}$ & $\frac{1}{x(x+1)}$ \\
\hline$a x+b$ & $a$ & $a^{x}$ & $a^{x}(a-1)$ \\
\hline$x^{2}$ & $2 x+1$ & $\log _{a} x$ & $\log _{a} \frac{x+1}{x}$ \\
\hline$x^{3}$ & $3 x^{2}+3 x+1$ & $\sin x$ & $2 \cos \left(x+\frac{1}{2}\right) \sin \frac{1}{2}$ \\
\hline$x^{n}$ & $\sum_{k=1}^{n} C_{n}^{k} x^{n-k}$ & $\cos x$ & $-2 \sin \left(x+\frac{1}{2}\right) \sin \frac{1}{2}$ \\
\hline
\end{tabular}

Запишемо формулу (3) у вигляді:

$$
\Delta f(x)=\frac{f(x+1)-f(x)}{1} .
$$

Тоді означення різницевого оператора стає певною мірою подібним до означення похідної (при цьому $\Delta x \rightarrow 0$ слід замінити на $\Delta x=1$ і прибрати символ границі). Неважко переконатися, що й властивості різницевого оператора $\Delta$ аналогічні властивостям похідної. В довіднику (Корн\&Корн, 1973) наводиться операторна формула, що пов'язує різницевий оператор з оператором диференціювання.

Наведемо правила знаходження різницевого оператора (та для порівняння правила знаходження похідної) для добутку на число, суми, різниці, добутку та частки двох функцій (Таблиця 2).

Табличя 2

Властивості різницевого оператора та похідної

\begin{tabular}{|c|c|c|}
\hline$f(x)$ & $\Delta \boldsymbol{f}(\boldsymbol{x})$ & $\boldsymbol{f}^{\prime}(\boldsymbol{x})$ \\
\hline$g(x) \pm h(x)$ & $\Delta g(x) \pm \Delta h(x)$ & $g^{\prime}(x) \pm h^{\prime}(x)$ \\
\hline$C g(x)$, де $C=$ const & $C \Delta g(x)$ & $C^{\prime}(x)$ \\
\hline$g(x) \cdot h(x)$ & aбo $\Delta g(x) h(x)+g(x+1) \Delta h(x)$, & $g^{\prime}(x) h(x)+g(x) h^{\prime}(x)$ \\
\hline$\frac{g(x)}{h(x)}$ & $g(x) \Delta h(x)+\Delta g(x) h(x+1)$ & $\frac{g^{\prime}(x) h(x)-g(x) h^{\prime}(x)}{(h(x))^{2}}$ \\
\hline
\end{tabular}

Приклад 2. Обчислити значення різницевого оператора від функцій: 1) $f(x)=2 x^{2}+2^{x}$; 2) $g(x)=2 x^{2} \cdot 2^{x}$.
1) $\Delta\left(2 x^{2}+2^{x}\right)=2 \cdot(2 x+1)+2^{x}$,
2) $\Delta\left(2 x^{2} \cdot 2^{x}\right)=2 x^{2} 2^{x}+2(2 x+1) 2^{x+1}=2^{x+1}\left(x^{2}+4 x+2\right)$.

Таким чином, різницевий оператор та похідна мають дуже схожі властивості. Зрештою, ця схожість є закономірною з огляду на те, що у деяких випадках, зокрема, при наближеному знаходженні розв'язків диференціальних рівнянь, похідну заміняють різницевим оператором. Відтак, можна розглянути можливість узагальнення понять похідної та різницевого оператора та їх відповідних характеристик. 
Таке узагальнення було запропоноване у 1988 році німецьким математиком Стефаном Хільгером та ґрунтується на понятті часової шкали як довільної непорожньої та замкненої (з погляду теорії множин) підмножини множини дійсних чисел. Відповідна теорія дозволяє розглядати об'єкти як на неперервних, так і на дискретних чи, навіть, на неперервнодискретних інтервалах. Ключовим поняттям (яке як раз і об'єднує в собі поняття похідної та різницевого оператора) у цій теорії є поняття так званої $\Delta$-похідної (дельта-похідної).

Перш ніж перейти до означення $\Delta$-похідної, розглянемо дві функції, які визначають вид кожного елемента заданої часової шкали.

Означення 5. (Bohner\&Peterson, 2001) На заданій часовій шкалі $\mathbb{T}$ функція $\sigma(x)=\inf \{t \in \mathbb{T}: t>x\}$ називається функцією стрибка вперед, функція $\rho(x)=\sup \{t \in \mathbb{T}: t<x\}$ називається функцією стрибка назад, а функція $\mu(x)=\sigma(x)-x$ називається функцією зернистості заданої часової шкали.

Таким чином, усі точки заданої часової шкали класифікуються відносно значень зазначених вище функцій у такий спосіб (Bohner\&Peterson, 2001):

1) якщо $x<\sigma(x)$, то $x$ - справа розсіяна точка;

2) якщо $x=\sigma(x)$, то $x$-справа щільна точка;

3) якщо $x>\rho(x)$, то $x$-зліва розсіяна точка;

4) якщо $x=\rho(x)$, то $x$ - зліва щільна точка;

5) якщо $\rho(x)<x<\sigma(x)$, то $x$ - ізольована точка;

6) якщо $\rho(x)=x=\sigma(x)$, то $x$ - щільна точка.

Тепер можемо дати означення $\Delta$-похідної функції $f(x)$, заданої на довільній часовій шкалі $\mathbb{T}$ (додатково будемо вважати, що у випадку sup $\mathbb{T} \neq \infty$, значення функції $\rho(\max \mathbb{T})=\max \mathbb{T})$.

Означення 5. (Bohner\&Peterson, 2001) Нехай $\mathbb{T}$ - задана часова шкала. $\Delta$-похідною заданої функції $f(x): \mathbb{T} \rightarrow \mathbb{R}$ в довільній точці $x_{0} \in \mathbb{T}$ називається функція $f^{\Delta}\left(x_{0}\right)$, яка задовольняє таку умову:

$$
\forall \varepsilon>0 \exists \delta(\varepsilon):\left|x-x_{0}\right|<\delta \Rightarrow\left|f(\sigma(x))-f\left(x_{0}\right)-f^{\Delta}\left(x_{0}\right) \cdot\left(\sigma(x)-x_{0}\right)\right| \leq \varepsilon\left|\sigma(x)-x_{0}\right| .
$$

Очевидно, умова (5) узагальнює умову (2) означення звичайної похідної. $\Delta$-похідна $f^{\Delta}(x)$ функції $є$ звичайною похідною $f^{\prime}(x)$ у випадку дійсного відрізка або визначає різницевий оператор $\Delta f(x)=f(x+1)-f(x)$ у випадку дискретного відрізка (зокрема, на множині цілих чисел). Більш того, має місце наступне твердження.

Теорема. (Bohner\&Peterson, 2001) Мають місце наступні твердження:

1) якщо функція $f(x) \epsilon$ диреренційовною у точці х у звичайному сенсі, то вона в чій точці є неперервною;

2) якщо х є справа розсіяною точкою часової шкали, але в дійсній області функція $f(x) \epsilon$ неперервною в цій точці, то $\Delta$-похідна функції $f(x)$ в чій точці має значення

$$
f^{\Delta}(x)=\frac{f(\sigma(x))-f(x)}{\mu(x)} ;
$$

3) якщо х є справа щільною точкою часової шкали, то функція $f(x) \epsilon$ диференційовною в цій точці, тоді і тільки тоді, коли існує скінченна границя

$$
\lim _{t \rightarrow x} \frac{f(x)-f(t)}{x-t}
$$

Значення чієї границі і $є$ заченням $\Delta$-похідна функції $f(x)$ в чій точці

$$
f^{\Delta}(x)=\lim _{t \rightarrow x} \frac{f(x)-f(t)}{x-t} .
$$

Проілюструємо застосування останньої теореми для обчислення $\Delta$-похідної на прикладі.

Приклад 3. Обчислимо значення $\Delta$-похідної функції $f(x)=\cos a x$, заданої на часовій шкалі $\mathbb{T}=\left[0 ; \frac{1}{2}\right] \cup\{1,2,3\} \cup$ $[4 ;+\infty)$.

Використовуючи попередню теорему, будемо мати:

1) якщо $x \in\left[0 ; \frac{1}{2}\right) \cup[4 ;+\infty)$, то $x$ - справа щільна точка і тому $(\cos a x)^{\Delta}=(\cos a x)^{\prime}=-a \sin a x$;

2) якщо $x=\frac{1}{2}$, то $(\cos a x)^{\Delta}=\frac{f\left(\sigma\left(\frac{1}{2}\right)\right)-f\left(\frac{1}{2}\right)}{\mu\left(\frac{1}{2}\right)}=\frac{f(1)-f\left(\frac{1}{2}\right)}{\frac{1}{2}}=2 \cdot\left(\cos a-\cos \frac{a}{2}\right)$;

3) якщо $x \in\{1,2,3\}$, то $x$ - справа розсіяна точка і

$$
(\cos a x)^{\Delta}=\frac{f(\sigma(x))-f(x)}{\mu(x)}=f(x+1)-f(x)=\cos a(x+1)-\cos a x .
$$

\section{ОБГОВОРЕННЯ}

3 викладеного вище випливає, що вивчення елементів теорії часових шкал, зокрема, $\Delta$-похідної функції та їі властивостей дає можливість узагальнити знання студентів з математичного аналізу і дискретної математики та комплексно підійти до розв'язування низки прикладних задач. Відповідне завдання було реалізоване одним із авторів статті в рамках спецкурсу «Вибрані питання сучасної математики», який тривалий час викладався для студентівмагістрантів спеціальності «Математика» у Сумському державному педагогічному університеті імені А.С.Макаренка.

Виходячи з того, що на вказаному освітньому рівні студенти добре володіють основними поняттями та інструментами диференціального числення, а деякі з них знайомі з різницевим численням, вивчення $\Delta$-похідної з одного боку дозволяє узагальнити їх знання щодо похідної функції неперервного аргументу та різницевого оператора, сформувати цілісне уявлення про ці два поняття та чітко розуміти межі їх використання, а з іншого - провести певні паралелі між ї властивостями та застосуваннями, і, як наслідок, - встановити зв'язки між різницевим та диференціальним численням. Наявність відповідних знань у майбутніх вчителів математики важко переоцінити, бо вони не лише відіграють певну роль у фундаментальній математичній підготовці, формуванні певного рівня математичної культури та наукового 
світогляду, а й сприяють більш глибокому розумінню сутності прикладної і практичної спрямованості математики та оволодінню їі методами.

\section{ВИСНОВКИ ТА ПЕРСПЕКТИВИ ПОДАЛЬШОГО ДОСЛІДЖЕННЯ}

Встановлення зв'язків між моделями і методами дослідження, які використовуються при вивченні різних математичних дисциплін, що входять у програму підготовки майбутніх фахівців-математиків, дозволяє сформувати у студентів цілісне уявлення про математичні об'єкти, алгоритми і теорії, і як наслідок, робить їх знання системними і практично більш значущими. Це сприяє інтелектуальному розвитку студентів, формуванню в них системних математичних знань, підвищенню рівня математичної грамотності та інтересу до предмету.

Зазначимо також, що спеціальна теорія часових шкал дає можливість поширити інтегрований підхід щодо вивчення похідної та різницевого оператора на вивчення обернених перетворень та відповідних понять - первісної (інтеграла) та антирізницевого оператора, що є дискретним аналогом оператора інтегрування.

\section{Список використаних джерел}

1. Андерсон Дж. А. Дискретная математика и комбинаторика. М.: Изд. дом «Вильямс», 2004. 960 с.

2. Гельфонд А .О. Исчисление конечных разностей. М.: Гос. изд-во физ.-мат. лит-ры, 1959. 400 с.

3. Завало С.Т. Курс алгебри. К.: Вища школа, 1985. 503 с.

4. Корн Г., Корн Т. Справочник по математике (для научных работников и инженеров). М.: Наука, 1973. 832 с.

5. Страх О.П., Лукашова Т.Д. Міждисциплінарні зв'язки при вивченні деяких тем дискретної математики та дифереціальних рівнянь. Фізико-математична освіта, 2021. Вип. 3 (29). С. 112-118.

6. Фихтенгольц Г.М. Основы математического анализа. Т.1. М.: Наука, 1968. 440 с.

7. Ядренко М.Й. Дискретна математика: Навчальний посібник. К.: "ТВіМС", 2004. 245 с.

8. Bohner M., Peterson A. Dynamic equations on time scales. An introduction with applications. Birkhäuser Boston Inc., Boston, MA, 2001. $360 \mathrm{p}$.

9. Kelley W., Peterson A. Difference Equations: An Introduction with Applications (Second edition). Academic Press, 2001.403 p.

\section{References}

1. Anderson, J.A. (2004). Discrete Mathematics with Combinatorics [Diskretnaja matematika i kombinatorika]. Moskow: Ed. house "Williams" [in Russian]

2. Gelfond, A.O. (1959). Finite Difference Calculus [Ischislenie konechnyh raznostej]. M.: State. publishing house physical-mat. lit-ry [in Russian]

3. Zavalo, S.T. (1985). Course of Algebra [Kurs alhebry]. K.: High school [in Ukrainian].

4. Korn, G. \& Korn, T. (1973). Handbook of mathematics (for scientists and engineers) [Spravochnik po matematike (dlja nauchnyh rabotnikov i inzhenerov)]. M.: Science [in Russian]

5. Strakh, O.\& Lukashova, T. (2021). Mizhdystsyplinarni zviazky pry vyvchenni deiakykh tem dyskretnoi matematyky ta dyferetsialnykh rivnian [Interdisciplinary connections in the study of some topics of discrete mathematics and differential equations]. Fizyko-matematychna osvita - Physical and Mathematical Education, 3 (29), 112-118 [in Ukrainian].

6. Fikhtengolts, G.M. (1968). Fundamentals of mathematical analysis [Osnovy matematicheskogo analiza]. V.1. M.: Science [in Russian].

7. Yadrenko, M.Y. (2004). Discrete Mathematics: A Textbook [Dyskretna matematyka: Navchalnyi posibnyk]. K.: "TViMS" [in Ukrainian].

8. Bohner, M. \& Peterson, A. (2001). Dynamic equations on time scales. An introduction with applica- tions. Birkhäuser Boston Inc., Boston, MA.

9. Kelley, W. \& Peterson, A. (2001). Difference Equations: An Introduction with Applications (Second edition). Academic Press.

\section{INTEGRATED APPROACH TO DEFINITION OF DERIVATIVE OF FUNCTIONS, WHICH IS DEFINED ON CONTINUOUS AND DISCRETE SETS \\ T.D. Lukashova, O.P. Strakh \\ Makarenko Sumy State Pedagogical University, Ukraine}

Abstract. The acquisition by a student of complex knowledge by studying generalizing theories and methods, the basic fundamental concepts are defined through which, is an important element in his training as a future specialist, in particular in the field of mathematics. Today there are a number of such theories, and their using is singled out even as methods of independent scientific directions. Applying elements of generalization and comparison of objects of study of different mathematical disciplines in the educational process, we also significantly contribute to the construction of interdisciplinary connections, which in turn have a positive impact on the comprehensive development of the future specialist and the realization of his potential in scientific and professional activities.

Formulation of the problem. Analysis of the main provisions of differential and difference calculus leads to the conclusion that there are significant similarities between the properties of the derivative and the difference operator, which are based characteristics of functions that are defined on continuous and discrete sets, respectively. It turns out that this similarity is not accidental, and these concepts are partial cases of the concept of delta derivative of function.

Materials and methods. The authors used the following research methods: systematic analysis of scientific, educational and methodological literature; comparison and synthesis of theoretical positions; monitoring the course of the pedagogical process; generalization of own pedagogical experience and experience of colleagues from other institutions of higher education. In addition, some general mathematical and special methods of differential and difference calculus and time scale theory were used.

Results. This article considers a general approach to the study of two fundamental mathematical concepts - the concept of derivative and difference operator, as well as ways to use this approach to establish connections between different mathematical theories in order to form a holistic view of mathematical objects, their properties and application. 
Conclusions. Establishing connections between models and research methods used in the study of various mathematical disciplines included in the training program for future specialists in mathematics, allows students to form a holistic view of mathematical objects, algorithms and theories, and as a consequence, makes them knowledge is systematic and practically more significant. This contributes to the intellectual development of students, the formation of their systematic mathematical knowledge, increasing the level of mathematical literacy and interest in mathematics.

Keywords: derivative, difference operator, delta derivative, differential calculus, difference calculus, continuous set, discrete set. 